\title{
TRY OUT SIMULATION TEST UNTUK PERSIAPAN SISWA MENGHADAPI UJIAN
}

\section{Try Out Simulation Test for Students to Prepare an Exam}

\author{
Aldo Wijaya ${ }^{1)}$, Fanny Fransisca ${ }^{1)}$ \\ ${ }^{1)}$ Teknik Informatika/Fakultas Sains dan Teknologi, Buddhi Dharma University \\ Diterima 13 Mei 2018 / Disetujui 31 Juli 2018
}

\begin{abstract}
Try out national exam on Junior High Schools is a schedule of activities that are very important for a school to increase the number of students graduation, try out or trial is also an activity that a student take in order to measure his ability to work on the problem on the final exam, from the case then it was designed a desktop-based try out simulation application. This application allows a student do several times try out and teachers can find out the mistakes of the students in try out simulation test. In general, students who want to follow the try out will be given an answer sheet and a sheet of questions and then round off the answer sheet after that the teacher will correct the work of students one by one and the possibility of a small mistake examination. The process of correcting it can be changed to be easier and simpler by using this application. This application can help teachers make problems and correct answers faster and teachers can more quickly know the weaknesses of the students and can teach the material further. This research succeeded in making try out simulation application for desktop based Junior High Schools study using vb.net and MSSQL. Based on the results of application testing conducted to several respondents indicate that this application helps students know their weaknesses respectively.

Keywords: Try Out, Simulation, National Exam, Desktop-Based..
\end{abstract}

\begin{abstract}
ABSTRAK
Try out ujian nasional Sekolah Menengah Pertama merupakan suatu jadwal kegiatan yang sangat penting bagi suatu sekolahan untuk meningkatkan angka kelulusan siswa didiknya, try out atau uji coba juga merupakan suatu kegiatan yang dilakukan seorang siswa agar dapat mengukur kemampuannya untuk mengerjakan soal pada ujian akhir, dari kasus tersebut maka dirancanglah sebuah aplikasi simulasi try out berbasis desktop. Aplikasi ini memungkinkan seorang siswa dapat melakukan beberapa kali try out dan guru dapat mengetahui kesalahan-kesalahan para siswa dalam mengerjakan soal ujian. Pada umumnya siswa yang ingin mengikuti try out akan diberikan lembar jawaban dan lembar soal lalu membulatkan lembar jawaban tersebut setelah itu guru akan mengoreksi hasil kerja siswa satu persatu dan kemungkinan kecil ada kesalahan pemeriksaan. Proses mengoreksi tersebut dapat dirubah menjadi lebih mudah dan sederhana dengan menggunakan aplikasi ini. Penerapan aplikasi ini dapat membantu guru membuat soal dan mengoreksi jawaban lebih cepat dan guru dapat lebih cepat mengetahui kelemahan para muridnya dan dapat mengajari materi tersebut lebih lanjut. Penelitian ini berhasil membuat aplikasi simulasi try out untuk Sekolah Menengah Pertama berbasis desktop menggunakan vb.net dan MSSQL. Berdasarkan hasil pengujian aplikasi yang dilakukan kepada beberapa responden menunjukkan bahwa aplikasi ini membantu para siswa mengetahui kelemahan mereka masing-masing.
\end{abstract}

Kata Kunci: Try Out, Simulasi, Ujian Nasional, Berbasis Desktop. 


\section{PENDAHULUAN}

Sekolah merupakan suatu institusi yang didalamnya terdapat komponen guru, siswa, dan staf administrasi yang setiap individu mempunyai tugas tertentu dalam menjalankan program. Sebagai institusi pendidikan formal, sekolah dituntut menghasilkan lulusan yang mempunyai kemampuan akademis tertentu, keterampilan, sikap dan mental, serta kepribadian lainnya sehingga mereka dapat melanjutkan ke jenjang pendidikan yang lebih tinggi atau bekerja pada lapangan pekerjaan yang membutuhkan keahlian dan keterampilannya.

Saat ini semakin banyak tempat bimbingan belajar dan sekolah yang menawarkan program test try out untuk ujian nasional. Tujuan utama di adakannya try out ujian nasional adalah melatih siswa agar siap untuk menghadapi ujian nasional sesungguhnya. Tidak sedikit siswa yang berminat ikut try out ujian nasional baik ikut di bimbingan belajar ataupun di sekolah masing-masing. Dalam melakukan pengoreksian lembar jawaban latihan ujian membutuhkan waktu yang lama karena masih bersifat manual. Sebagian siswa yang berminat ikut try out ikut pada lembagalembaga pendidikan yang menawarkan try out ujian nasional sehingga kesulitan mengukur kemampuan masing-masing siswa dalam menghadapi ujian.

Dalam hal ini sepertinya perlu untuk membuat suatu aplikasi berbasis desktop dengan menggunakan bahasa pemrograman Visual Basic dan database MSSQL untuk jangka panjang yang didalamnya berisi tentang informasi dan soal-soal yang biasa diujikan di ujian nasional, guna melatih dan memantau kesiapan siswa dalam menghadapi ujian nasional.

*Korespondensi Penulis:

E-mail: aldo.wijaya95@gmail.com

\section{STUDI PUSTAKA}

\section{Simulasi \\ Menurut Udin Syaefudin Sa'ud (2009:129) Simulasi adalah sebuah}

replikasi atau visualisasi dari perilaku sebuah sistem, misalnya sebuah perencanaan pendidikan, yang berjalan pada kurun waktu yang tertentu. Jadi dapat dikatakan bahwa simulasi itu adalah sebuah model yang berisi seperangkat variabel yang menampilkan ciri utama dari sistem kehidupan yang sebenarnya. Simulasi memungkinkan keputusan-keputusan yang menentukan bagaimana ciri-ciri utama itu bias dimodifikasikan secara nyata.

Tujuan simulasi adalah untuk pelatihan (training), studi perilaku sistem (behaviour), dan hiburan/permainan (game). Simulasi memeiliki beberapa kelebihan, diantaranya: (Syaefudin, 2009)

7. Simulasi mampu menggambarkan suatu prosedur operasional untuk rentang waktu yang lebih singkat dari perencanaan.

8. Simulasi mampu menyajikan sistem nyata yang lebih besar dan rumit atau kompleks, dibandingkan dengan model matematika yang masih konvensional.

9. Dengan simulasi, penggunanya dapat menjadikan hasil simulasi sebagai pengambilan keputusan misalnya untuk penerapan sistem maupun memutuskan langkah-langkah prefentif aspek lainnya.

Selain kelebihan, tentunya simulasi juga memiliki beberapa kelemahan, seperti:

5. Simulasi bukan merupakan proses optimasi, tetapi menghasilkan cara untuk menilai suatu solusi, simulasi tidak menghasilkan solusi.

6. Pembuatan simulasi memerlukan waktu yang cukup lama mengingat harus merepresentasikan kondisi nyata dan juga biaya yang diperlukan cukup besar untuk simulasi kasus yang kompleks.

7. Tidak semua kasus dapat disimulasikan karena untuk kasus yang menuntut kepastian akan sangat sulit menggunakan simulasi.

\section{Pengertian Try Out}

Menurut Terry Overton (2008:34), ujian adalah suatu metode untuk menentukan kemampuan siswa menyelesaikan sejumlah tugas tertentu atau mendemostrasikan penguasaan suatu 
keterampilan atau pengetahuan pada suatu materi pelajaran.

Lalu, ujian juga dianggap sebagai pengukuran terencana yang dipakai guru untuk mencoba menciptakan kesempatan bagi para siswanya untuk memperlihatkan prestasi mereka dalam kaitannya dengan tujuan yang telah ditentukan (Cangelosi, 2007).

Menurut Dasna (2009:7), try out sebagai salah satu upaya mengukur kemampuan siswa sudah ada pada jalur yang tepat karena kegiatan itu dapat memberikan gambaran tentang kompetensi yang telah dicapai/dikuasai oleh siswa, dan memberikan pengalaman kepada siswa mengerjakan tes sebagaimana yang akan dilakukan pada UN. Bila try out yang dilakukan menggunakan soal-soal model UN maka hasil yang diperoleh akan menjadi bahan perenungan bagi siswa dan sekolah untuk optimalisasi upaya dan usaha agar mencapai hasil yang optimal pada saatnya.

\section{Pengertian Ujian Nasional}

Ujian Nasional adalah upaya pemerintah untuk mengevaluasi tingkat pendidikan secara nasional dengan menetapkan standarisasi nasional pendidikan. Hasil dari Ujian Nasional yang diselenggarakan oleh Negara adalah upaya pemetaan masalah pendidikan dalam rangka menyusun kebijakan pendidikan nasional. Berdasarkan pendapat tersebut tentang Ujian Nasional maka dapat disimpulkan bahwa Ujian Nasional adalah sistem evaluasi atau penilaian standar pendidikan dasar dan menengah secara nasional dengan menetapkan standarisasi nasional pendidikan yang bertujuan sebagai pemetaan masalah pendidikan dalam rangka menyusun kebijakan pendidikan nasional (Tilaar, 2008).

\section{Visual Basic .NET}

Menurut Wahana Komputer (2007:1), Visual Basic.NET merupakan salah satu bahasa pemrograman yang dapat digunakan untuk membuat program aplikasi. Bahasa pemrograman ini menyediakan beberapa tools untuk otomatisasi proses pengembangan, yaitu visual tools yang digunakan untuk melakukan beberapa operasi pemrograman dan desain umum dan juga fasilitas-fasilitas lain yang dapat menunjang dalam pemrograman.

Visual Basic merupakan salah satu bahasa pemrograman paling laris dan paling sukses di dunia. Dimana tercatat sampai pada tahun 2005 Visual Basic merupakan bahasa pemrograman yang paling banyak dipakai oleh para programmer bahkan diyakini sampai saat ini. Menjadi pilihan berbagai kalangan tentunya Visual Basic memiliki berbagai hal yang patut dijadikan alasan, selain bahasa pemrograman yang sangat (paling) mudah dipelajari oleh berbagai kalangan baik awam maupun ahli, Visual Basic yang didukung penuh oleh produsennya (Microsoft) selalu dikembangkan dan disesuaikan dengan kebutuhan zaman seperti penyesuaian model pemrograman modern yang berbasis OOP (Object Oriented Programming) (A.M.Hirin, 2011:2).

\section{Unified Modelling Language (UML)}

Menurut Nugroho (2009:6), UML (Unified Modelling Language) adalah "bahasa" pemodelan untuk sistem atau perangkat lunak yang berparadigma "berorientasi objek". Pemodelan (modelling) sesungguhnya digunakan untuk penyederhanaan permasalahanpermasalahan yang kompleks sedemikian rupa sehingga lebih mudah dipelajari dan dipahami.

Menurut Herlawati \& Widodo (2011:10), bahwa beberapa literatur menyebutkan bahwa UML menyediakan sembilan jenis diagram, yang lain menyebutkan delapan karena ada beberapa diagram yang digabung, misalnya diagram komunikasi, diagram urutan dan diagram pewaktuan digabung menjadi diagram interaksi.

Namun demikian model-model itu dapat dikelompokkan berdasarkan sifatnya yaitu statis atau dinamis. Jenis diagram itu antara lain: (Herlawati \& Widodo, 2011)

\section{Use Case Diagram untuk memodelkan} proses bisnis. 
22.Conceptual Diagram untuk memodelkan konsep-konsep yang ada di dalam aplikasi.

23. Sequence Diagram untuk memodelkan pengiriman pesan (message) antar objek.

24.Collaboration Diagram untuk memodelkan interaksi antar objek.

25.State Diagram untuk memodelkan perilaku objects di dalam sistem.

26.Activity Diagram untuk memodelkan perilaku Use Case dan objek di dalam sistem.

27.Class Diagram untuk memodelkan struktur kelas.

28.Object Diagram untuk memodelkan struktur objek.

29.Component Diagram untuk memodelkan komponen objek.

30.Deployment Diagram untuk memodelkan distribusi aplikasi.

\section{Entity Relationship Diagram (ERD)}

Menurut Yuniar Supardi (2010:20)

ERD merupakan salah satu alat (tool) berbentuk grafis, yang populer untuk desain database". ERD memiliki beberapa komponen, yaitu entitas, atribut, relasi, dan kardinalitas. Entitas adalah suatu objek dan memiliki nama. Suatu sistem tidak akan berjalan normal tanpa adanya entitas. Contoh entitas pada lingkungan kampus adalah 'MAHASISWA'. Dalam entitas 'MAHASISWA', berisi elemen-elemen data seperti NIM, Nama, Alamat, dan sebagainya yang disebut sebagai atribut. Dalam sebuah sistem juga terdapat relasi antar entitas ini juga ditandai dengan adanya kardinalitas. Kardinalitas ini menentukan entitas kuat dan entitas lemah. Terdapat tiga derajat kardinalitas, yaitu one to one, one to many, dan many to many.

\section{Storyboard}

$\begin{array}{r}\text { Storyboard merupakan } \\ \text { pengorganisasian grafik, contohnya }\end{array}$
sederetan ilustrasi atau gambar yang
ditampilkan berurutan untuk keperluan
visualisasi awal dari suatu file, animasi atau
urutan media interaktif, termasuk
interaktifitas di web. Storyboard visualisasi
ide dari aplikasi yang akan dibangun
sehingga dapat memberikan gambaran dari
aplikasi yang akan dihasilkan. Storyboard
dapat dikatakan juga visual script yang akan di jadikan outline dari sebuah proyek, ditampilkan shot by shot yang biasa disebut dengan istilah scene. (Binanto, 2010)

\section{Structured Query Language (SQL)}

Menurut Sari Armiati dan Shiyami Milwandhari (2016:8), perintah SQL merupakan perintah untuk mengolah, menampilkan, dan memanipulasi data yang tersimpan dalam sebuah RDBMS (Relational Database Management System). Terdapat beberapa aturan yang harus diperhatikan saat menulis perintah SQL, yaitu sebagai berikut:

1. Perintah SQL tidak case sensitive artinya tidak dibedakan antara penulisan huruf kecil dan huruf besar.

2. Perintah SQL dapat terdiri dari lebih dari satu baris.

3. Kata kunci pada perintah SQL tidak bisa disingkat atau dipisah di baris yang berbeda.

4. Klausa biasanya ditempatkan di baris yang berbeda.

5. Gunakan indentasi untuk setiap klausa untuk mempermudah pembacaan perintah.

6. Setiap perintah SQL diakhiri dengan tanda titik koma.

7. Penulisan komentar pada perintah SQL menggunakan tanda minus dua kali.

\section{METODOLOGI PENELITIAN}

Sekolah Citra Kasih Tangerang merupakan lembaga pendidikan swasta dibawah naungan Yayasan Citra Kasih yang diawasi oleh pemerintah, berlokasi di Jl. Delta Raya No.1, Komplek Perumahan Cimone Permai, Tangerang. Pada awal berdirinya Sekolah Citra Kasih hanya memiliki Taman Kanak-kanak, didirikan pada tahun 1986 kemudian 1 tahun berikutnya didirikan SD Citra Kasih dengan akta notaris/lembaga No. 8 tanggal 4 Juni 1987 dan No. Pendaftaran 151/SD/JB/XI/1987.

Melihat antusiasme masyarakat terhadap berdirinya TK dan SD Citra Kasih, Yayasan Pendidikan Citra Kasih mulai meningkatkan pelayanan pendidikannya dengan mendirikan SMP dan SMA Citra 
Kasih dengan akta notaris no. 26 tanggal 11 Agustus 2001. Sekolah Citra Kasih merupakan sekolah swasta yang terakreditasi, menurut Badan Akreditasi Sekolah Nasional, TK, SD, SMP dan SMA Citra Kasih merupakan sekolah swasta dengan status terakreditasi A.

Adapun visi dari Sekolah Citra Kasih ialah menjadi lembaga pendidikan yang unggul dalam Iman, ilmu dan teknologi. Serta memiliki misi untuk unggul dalam memajukan tunas bangsa.

\section{Langkah-Langkah Penelitian}

Peneliti menggunakan langkahlangkah dibawah ini untuk mengembangkan seluruh hasil penelitian:

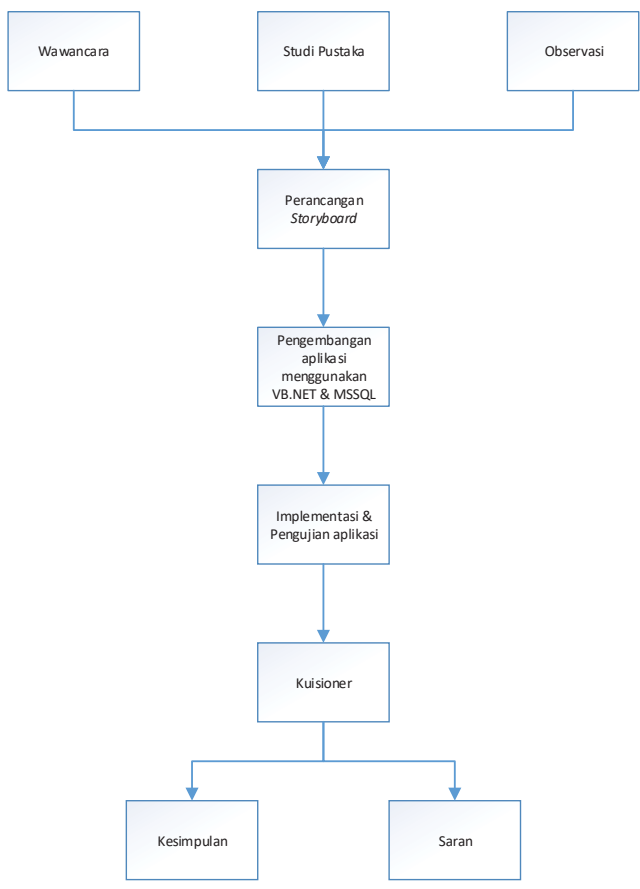

Gambar 1. Langkah-Langkah Penelitian

\section{Activity Diagram}

Berikut ini adalah gambar activity diagram sistem berjalan di Sekolah Citra Kasih Tangerang.

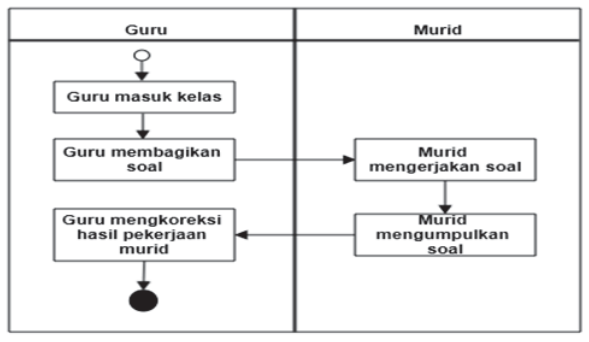

Gambar 2. Activity Diagram

\section{Entity Relationship Diagram (ERD)}

Berikut ini adalah gambar entity relationship diagram untuk aplikasi simulasi try out ini:

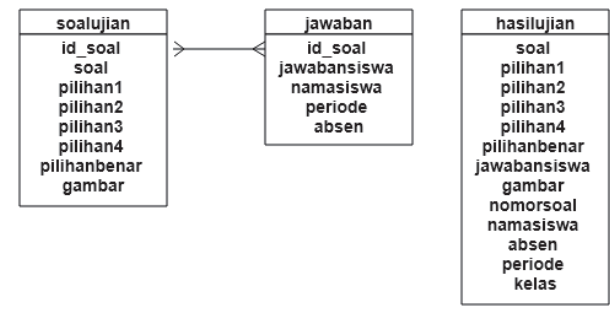

Gambar 3. Entity Relationship Diagram

\section{Analisa Perancangan}

Berikut ini adalah perancangan desain pada aplikasi simulasi try out ini:

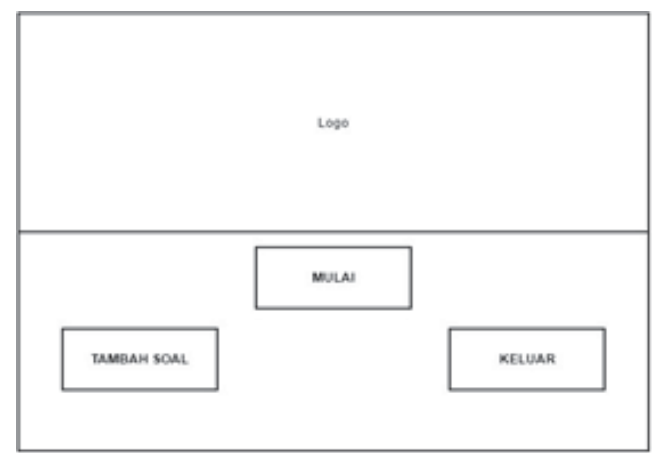

Gambar 4. Halaman Menu Utama

Tampilan menu utama atau menu utama ini tersedia 4 tombol mulai, Aturan, tambah soal, Keluar yang fungsinya berbeda-beda. 


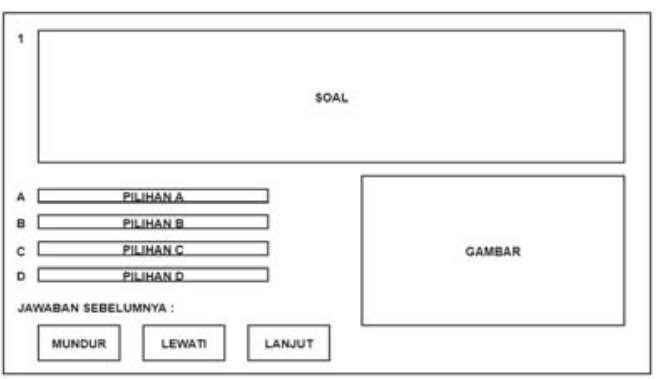

Gambar 5. Halaman Mulai Tes

Pada tampilan menu mulai ini muncul tampilan ujian dengan soal beserta pilihan jawabannya dan ada timer-nya. Ada tombol untuk menyimpan jawaban dan melewati soal.

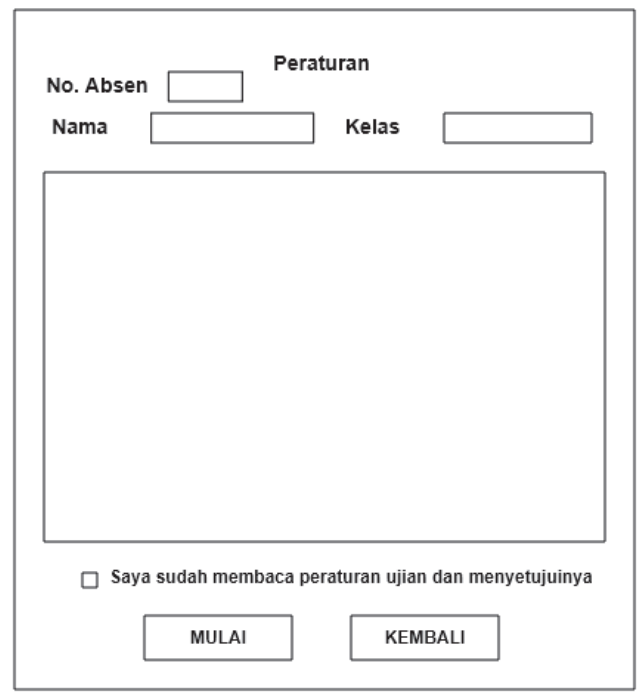

Gambar 6. Halaman Data Siswa

Tampilan ini berisikan kotak teks dan aturan-aturan selama ujian berlangsung.

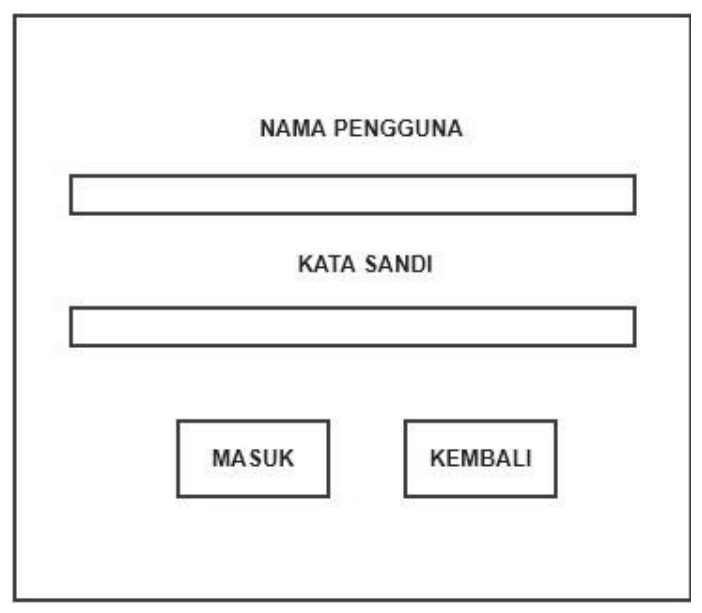

Gambar 7. Halaman Login Guru

Tampilan menu login isinya username dan password yang hanya untuk guru.

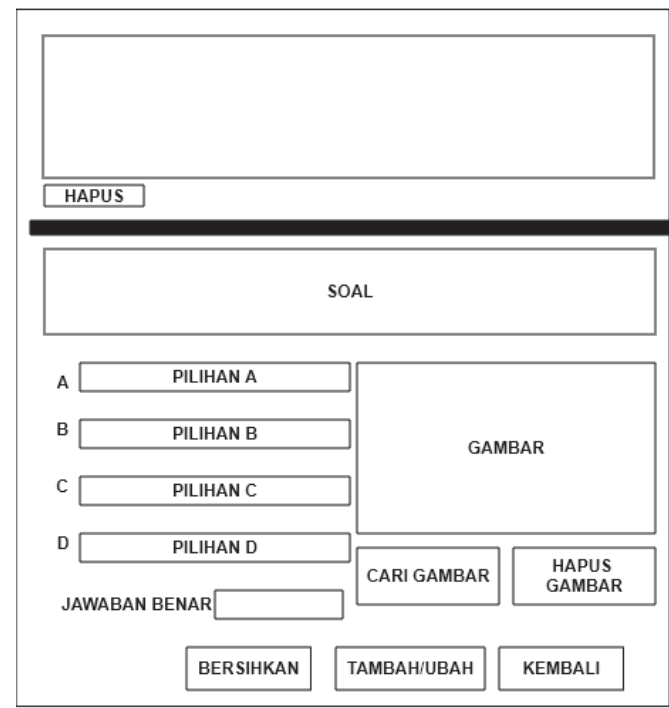

Gambar 8. Halaman Tambah Soal

Menu tambah soal ini khusus guru. Yang isinya banyak kotak-kotak yang di isi oleh guru untuk membuat soal ujian yang diberikan ke murid nanti.

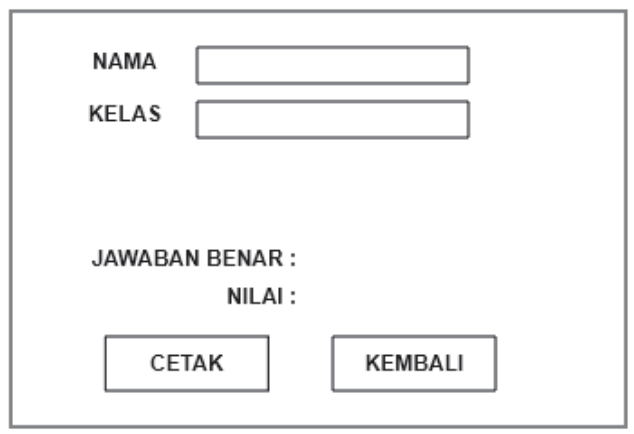

Gambar 9. Halaman Cetak

Menu ini akan muncul setelah siswa/i selesai mengerjakan soal-soal ujian yang diberikan. 
Apakah kamu ingin menutup aplikasi ini?
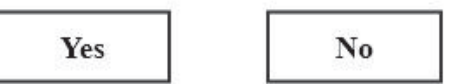

Gambar 10. Halaman Keluar

Terdapat pilihan tombol Yes dan No. Jika Yes maka akan keluar dari aplikasi dan jika No maka akan tetap pada menu tersebut.

\section{HASIL DAN PEMBAHASAN}

\section{Hasil Tampilan}

Berikut ini adalah hasil tampilan desain pada aplikasi simulasi try out ini:

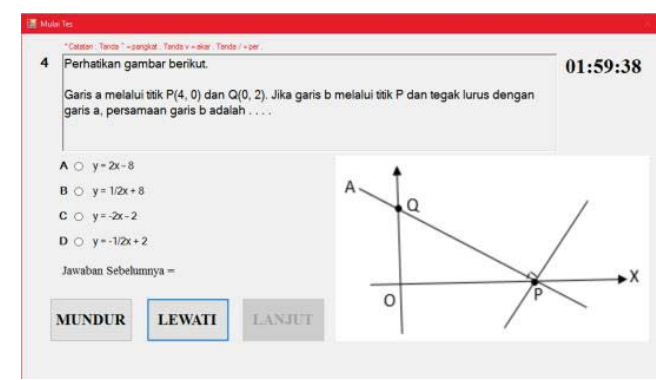

Gambar 11. Tampilan Mulai Tes

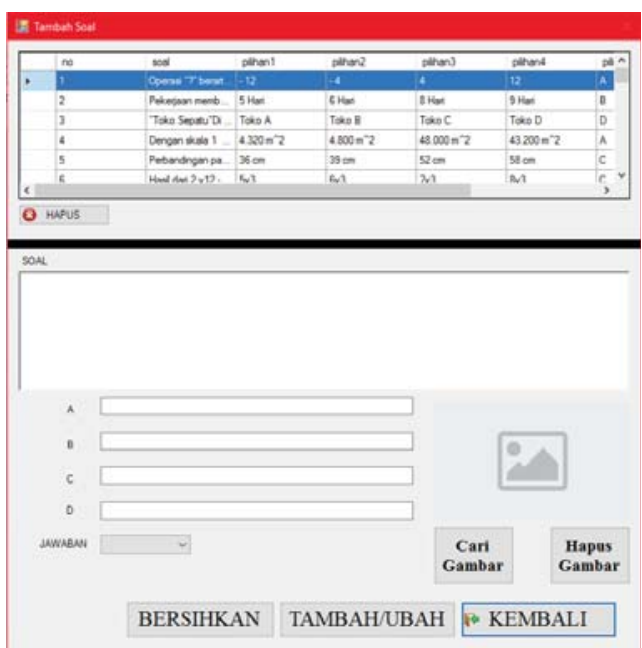

Gambar 12. Tampilan Tambah Soal

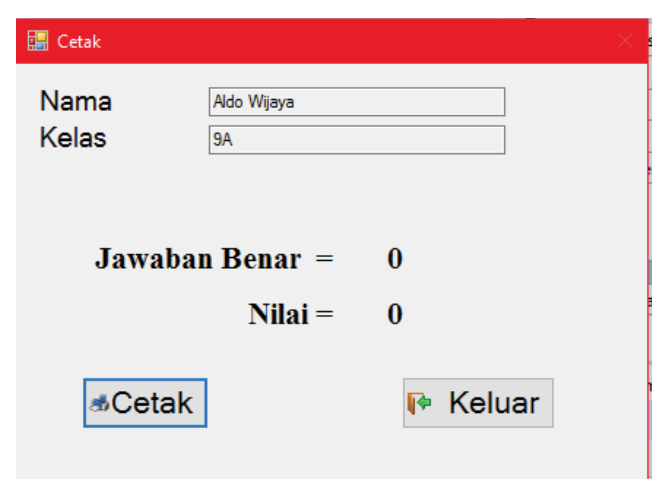

Gambar 13. Tampilan Cetak

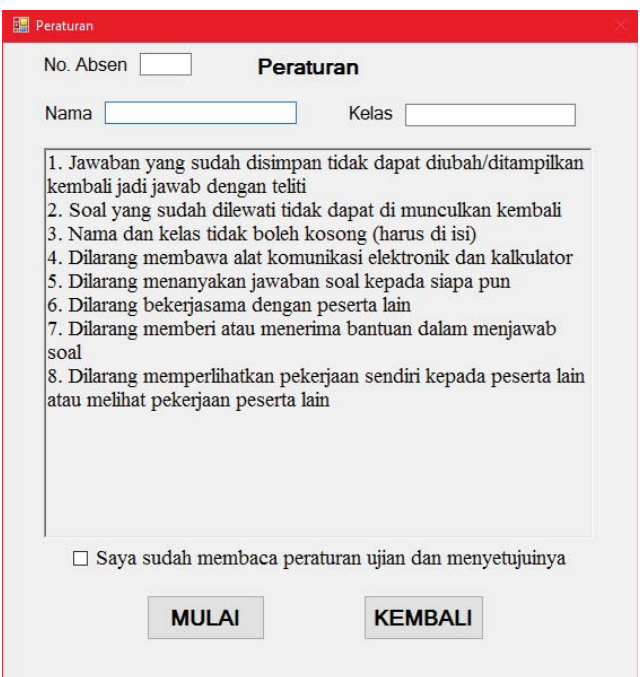

Gambar 14. Tampilan Data Siswa

\section{廌 Masuk}

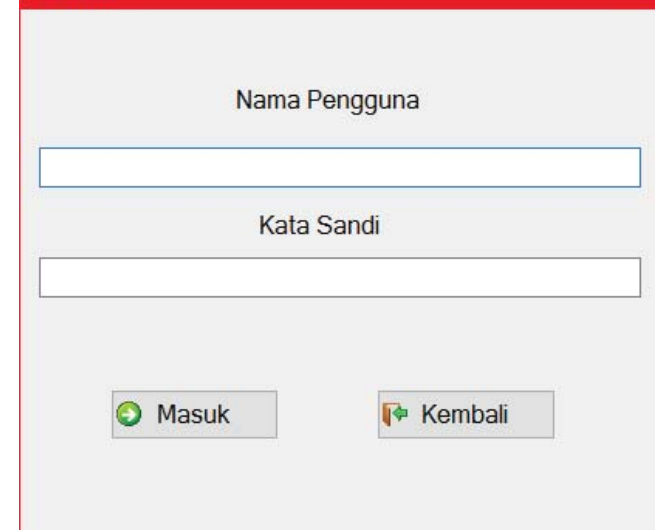

Gambar 15. Tampilan Login

\section{Keluar}

Apakah kamu ingin menutup aplikasi ini?

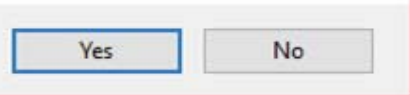


Gambar 16. Tampilan Keluar

\section{Hasil Pengolahan Data Kuisioner}

Untuk mengetahui hasil dari aplikasi yang telah dibuat, penulis menggunakan kuesioner sebagai media pengumpulan data. Dari hasil kuesioner tersebut kita dapat mengetahui tanggapan responden mengenai aplikasi yang dibuat. Satu lembar kuesioner berisikan 10 (sepuluh) pertanyaan dan dibagikan kepada 10 (sepuluh) responden yang diuraikan sebagai berikut:

Tabel 1. Hasil Data Kuisioner

\begin{tabular}{|c|c|c|c|}
\hline No & Pertanyaan & $\mathrm{Ya}$ & Tidak \\
\hline 1 & $\begin{array}{l}\text { Apakah anda } \\
\text { menyukai aplikasi } \\
\text { ujian berbasis } \\
\text { komputer? }\end{array}$ & 8 & 2 \\
\hline 2 & $\begin{array}{l}\text { Apakah aplikasi } \\
\text { ujian ini mudah } \\
\text { untuk digunakan? }\end{array}$ & 10 & 0 \\
\hline 3 & $\begin{array}{l}\text { Apakah aplikasi ini } \\
\text { memiliki tampilan } \\
\text { yang menarik? }\end{array}$ & 3 & 7 \\
\hline 4 & $\begin{array}{l}\text { Apakah penjelasan } \\
\text { peraturan dan cara } \\
\text { penggunaan aplikasi } \\
\text { ini mudah di } \\
\text { mengerti? }\end{array}$ & 8 & 2 \\
\hline 5 & $\begin{array}{l}\text { Apakah gambar yang } \\
\text { terdapat pada } \\
\text { aplikasi ini dapat } \\
\text { jelas terlihat? (tidak } \\
\text { terlalu kecil atau } \\
\text { terlalu besar) }\end{array}$ & 6 & 4 \\
\hline 6 & $\begin{array}{l}\text { Apakah anda dapat } \\
\text { mendapat kesulitan } \\
\text { saat menggunakan } \\
\text { aplikasi ini? }\end{array}$ & 1 & 9 \\
\hline 7 & $\begin{array}{l}\text { Apakah anda } \\
\text { menjadi lebih mudah } \\
\text { mengetahui } \\
\text { kelemahan anda pada } \\
\text { soal matematika } \\
\text { dengan } \\
\text { menggunakan }\end{array}$ & 9 & 1 \\
\hline
\end{tabular}

aplikasi ini?

8 Apakah anda $\quad 8 \quad 2$

menyukai mengisi

soal ujian di aplikasi

ini?

9 Apakah masih

64

terdapat banyak

kekurangan pada

aplikasi ini?

10 Secara keseluruhan, $\quad 8 \quad 2$ apakah anda menyukai aplikasi ini?

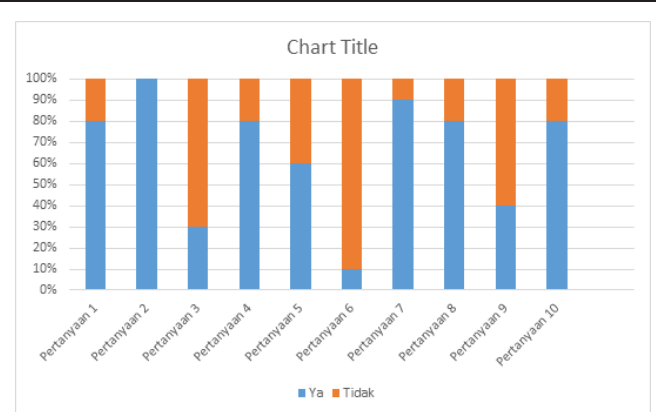

Gambar 17. Grafik Hasil Kuisioner

\section{KESIMPULAN DAN SARAN}

\section{Kesimpulan}

Setelah dilakukan perancangan, pembuatan, dan pengujian aplikasi serta melakukan kuesioner terhadap para pengguna aplikasi ini, maka peneliti menarik kesimpulan sebagai berikut:

6. Dengan adanya aplikasi ini siswa/i menjadi lebih mudah mengetahui kelemahan mereka masing-masing pada soal-soal tertentu.

7. Guru menjadi mudah mengetahui kelemahan tiap murid dan dapat mengajarkannya lebih lanjut pada murid tersebut.

\section{Saran}

Dalam penerapannya, aplikasi ini masih jauh dari kata sempurna dan masih banyak memiliki kekurangan. Agar penggunaan aplikasi ini dapat lebih 
maksimal, peneliti memberikan beberapa saran, antara lain:

10.Aplikasi ini dapat dikembangkan dan digunakan di smartphone atau ponsel pintar.

11.Aplikasi ini dapat mencetak hasil kerja siswa/i lebih baik dan bagus dan menampilkan soal-soal dan pilihan lebih rapih dengan gambar yang lebih besar.

12.Aplikasi ini tidak dapat menganalisa bobot dari soal-soal yang dimasukkan apakah itu rendah, sedang, atau tinggi.

13.Aplikasi ini tidak dapat memperlihatkan apakah siswa lulus KKM atau tidak.

14.Aplikasi ini tidak dapat diisi soal essay atau jawaban essay.

\section{DAFTAR PUSTAKA}

A.M. Hirin (2011). VB .Net : Belajar Tuntas Dari Dasar Sampai Mahir. PT. Prestasi Pustaka Raya, Jakarta.

Armiati, Sari \& Shiyami Milwandhari (2016). Basis Data Oracle Fundamental. Deepublish, Jakarta

Binanto, Irwan (2010). Multimedia digital, dasar teori pengembangan. Andi, Yogyakarta.

Cangelosi, James (2007). Merancang Tes Untuk Menilai Prestasi Siswa. ITB, Bandung.

Dasna I. W. (2009). Telaah Soal Persiapan Ujian Nasional. Malang: Universitas Negeri Malang. On Line at http:Ip3um.net/kegiatan/23.html [accessed 26 April 2011].
H. A. R. Tilaar (2008). Standarisasi Pendidikan Nasional: Suatu Tinjuan Kritis. Jakarta: Rineka Cipta. Hal 109-110.

Nugroho, Adi (2009). Rekayasa Perangkat Lunak Menggunakan UML \& Java. Andi, Yogyakarta.

Overton, Terry. (2008). Assessing Learners with Special Needs: An Applied Approach. Pearson, New Jersey.

Supardi, Yuniar. (2010). Semua Bisa Menjadi Programmer Java - Study Case. PT Elex Media Komputindo, Jakarta.

Syaefudin, Udin Sa'ud (2009), Perancanaan Pendidikan Pendekatan Komprehensif. PT Remaja Rosdakarya, Bandung.

Wahana Komputer (2007). Pemrograman Visual Basic .Net 200. Andi, Semarang. 